\title{
COMPARISON OF WAVELET NETWORK AND Logistic REgRESSION IN PREDICTING ENTERPRISE FINANCIAL DISTRESS
}

\author{
Ming-Chang Lee ${ }^{1}$ and $\mathrm{Li}-\mathrm{Er} \mathrm{Su}^{2}$ \\ ${ }^{1}$ National Kaohsiung University of Applied Sciences \\ ${ }^{2}$ Shih Chien University, Kaohsiung Campus, Kaohsiung Taiwan
}

\begin{abstract}
Enterprise financial distress or failure includes bankruptcy prediction, financial distress, corporate performance prediction and credit risk estimation. The aim of this paper is that using wavelet networks in non-linear combination prediction to solve ARMA (Auto-Regressive and Moving Average) model problem. ARMA model need estimate the value of all parameters in the model, it has a large amount of computation. Under this aim, the paper provides an extensive review of Wavelet networks and Logistic regression. It discussed the Wavelet neural network structure, Wavelet network model training algorithm, Accuracy rate and error rate (accuracy of classification, Type I error, and Type II error). The main research opportunity exist a proposed of business failure prediction model (wavelet network model and logistic regression model). The empirical research which is comparison of Wavelet Network and Logistic Regression on training and forecasting sample, the result shows that this wavelet network model is high accurate and the overall prediction accuracy, Type I error and Type II error, wavelet networks model is better than logistic regression model.
\end{abstract}

\section{KEYWORDS}

Wavelet Networks; Logistic Regression; Business Failure Prediction; Type I error; Type II error.

\section{INTRODUCTION}

Business Failure Prediction (BFP) can help to avoid investing in business likely to fail. Bankruptcy prediction model enhance the decision support tool and improve decision making [33]. It uses statistical analysis and data mining technique. Statistical business failure prediction models attempt to predict the business' failure or success. The Multiple discriminant analysis (MDA) has been the most popular approaches $[6,13]$. There have a large number of alternative techniques available in this MAD model $[2,9,22,33]$. The data mining techniques include decision tree, support vector machine (SVM) [10], neural networks (NNs) [11], fuzzy system, rough set theory and genetic algorithm (GA) [33]. Various researches have demonstrated the artificial intelligence (AI) techniques serve as a useful tool bankruptcy prediction such as artificial neural networks (ANNs) [30].

The following method or model using for prediction in time series are Box-Jenkins method [28], Grey forecasting model [11], artificial neural networks model [1, 4, 16], Logistic Regression [25, 30], ARMA Model [21]. In Box-Jenkins method, it is difficult to determine the model features; it is also difficult to identify no-steady state. It is not need to calculate the statistical characters in grey forecasting model or neural network model. But, grey forecasting model is suitable for solve exponential growth practical problems. The network modelling approach in artificial neural 
networks model is difficult to determine the network structure by using scientific application. In training and learning state, BP model calculate the optimal weight. This model trapped in a local minimum which will affect the reliability and accuracy of the model. ARMA Model provides one of the basic tools in time series modelling. This method is valid in pure AR model and pure MA model. But, it is difficult for identification in mixed ARMA model. Therefore, using wavelet network clustering capabilities, the input time series sample autocorrelation function (SACF) value and partial autocorrelation function (SPACF) value, the output is the identification of ARMA model. Many researchers [20, 29, 36] discussed the ability of nonlinear approximation of wavelets and neural network models. Some researches $[31,32,34]$ studied fuzzy wavelet neural network models for prediction and identification of dynamical systems.

The main contribution of this paper is to propose a financial distress prediction method based on Wavelet Network model and logistic regression model. The financial and non-financial ratios were used to enhance the accuracy of the financial distress prediction model. The dimension of the inputs was reduced using a principal component analysis (PCA) method, and then Wavelet Network model were used to predict the financial distress.

\section{LOGISTIC REGRESSION MODEL AND WAVELET NETWORK MODEL}

\subsection{Logistic regression model}

Defines the probability $\pi(x)$ and 1- $\pi(x)$, these probabilities are written in the following form:

$$
\begin{gathered}
\pi(x)=P\left(Y=1 \mid X_{1}, X_{2}, \ldots, X_{n}\right) \\
1-\pi(x)=P\left(Y=0 \mid X_{1}, X_{2}, \ldots, X_{n}\right)
\end{gathered}
$$

This model of the $\ln \frac{\pi(x)}{1-\pi(x)}$ is:

$$
\ln \frac{P\left(Y=1 \mid X_{1}, X_{2}, \ldots, X_{n}\right)}{1-P\left(Y=1 \mid X_{1}, X_{2}, \ldots, X_{n}\right)}=\ln \frac{\pi(x)}{1-\pi(x)}=\beta_{0}+\sum_{j=1}^{n} \beta_{j} X_{j}
$$

Using the inverse of the Logit transformation of (2), it obtains at the following:

$$
P\left(Y=1 \mid X_{1}, X_{2}, \ldots, X_{n}\right)=\frac{e^{\beta_{0^{+}} \sum_{j=1}^{n} \beta_{j} X_{j}}}{1+e^{\beta_{0^{+}} \sum_{j=1}^{n} \beta_{j} X_{j}}}=\frac{1}{1+e^{-\left(\beta_{0^{+}} \sum_{j=1}^{n} \beta_{j} X_{j}\right)}}
$$

(3) is a logistic regression model, the conditional mean is between 0 and 1.

\subsection{Maximum Likelihood Estimate (MLE)}

The maximum likelihood is the method of parameter estimation in logistic regression model. For a set of observations in the data $\left(x_{i}, y_{i}\right)$, the following equation results for the contribution to the likelihood function for the observation $\left(x_{i}, y_{i}\right)$ is $\alpha\left(x_{i}\right)$ :

$$
\alpha\left(x_{i}\right)=\pi\left(x_{i}\right)^{y_{i}}\left[1-\pi\left(x_{i}\right)^{1-y_{i}}\right]
$$

The observations are assumed to be independent of each other so it can multiply their likelihood contributions to obtain the complete likelihood function $l(\beta)$. The result is given in (5). Where $\beta$ is the collection of parameters $\left(\beta_{0}, \beta_{1}, \ldots, \beta_{n}\right)$ and $l(\beta)$ is the likelihood function of $\beta$. 
International Journal of Computer Science \& Information Technology (IJCSIT) Vol 7, No 3, June 2015

$$
l(\beta)=\prod_{i=1}^{n} \alpha\left(x_{i}\right)
$$

$L(B)$ is denoted the log likelihood expression.

$$
L(\beta)=\ln [l(\beta)]=\sum_{i=1}^{n}\left(y_{i} \ln \left[\pi\left(x_{i}\right)\right]+\left(1-y_{i}\right) \ln \left[1-\pi\left(x_{i}\right)\right]\right)
$$

It employs the techniques of calculus to determine the value of $\beta$ based on maximum of $L(\beta)$. It takes the derivate of $L(\beta)$ with respect to $\beta_{0}, \beta_{1}, \ldots, \beta_{n}$ and setting the resulting derivatives equal to zero. These equations are called likelihood estimations, and there is $n+1$ equation.

\subsection{Hypothesis testing}

The hypothesis testing that a coefficient on an independent variable is significantly different from zero use Wald statistic. The Wald statistic for the $\beta$ coefficient is:

$$
\chi^{2}=\mathrm{Wald}=[\beta / \sigma \beta]^{2}
$$

This is distributed chi-square with 1 degree of freedom.

\subsection{Wavelet network model t}

Wavelet analysis is a new technique designed for multi scale analysis in the time series modelling. Wavelet analysis utilizes the wavelet basis function to approximate and extract the features of interests from the original data. If the function $\varphi(t)$ satisfies the following condition is called wavelet basis function.

$$
\int_{0}^{\propto} \frac{|\varphi(w)|}{w} d w<\propto
$$

Where $\varphi(w)$ is the Fourier transform of $\varphi(t)$ in the frequency domain. Variable $\mathrm{t}$ can actually have other unit [12].

The wavelet basis function $\varphi_{a, b}(t)=\frac{1}{\sqrt{a}} \varphi\left(\frac{t-b}{a}\right)$

Where 'a' refers the scale (dilated) coefficient, 'b' refers the translation coefficient.

Wavelet networks employ activation function that are dilated and translated coefficient of a single function $\varphi: R^{d} \rightarrow R$, where $\mathrm{d}$ is the input dimension [36]. This function called the 'mother wavelet' is localized both in the space and frequency domains [7]. In order to increase convergence speed, the wavelet neural network shows surprising effectiveness in solving the conventional problem of poor convergence or even divergence encountered in other kind of neural network [38].

Wavelet network model is feed forward network model; the wavelet basis function is neuronal activation function. The basic strategy is changing the shape and scale wavelet basis, adjusting the network weights and threshold value to take the error function minimization. Figure 1 is Wavelet neural network structure.

Three layers of the wavelet neural network are input layer, hidden layer and output layer. Each layer is fully connected to the nodes in the next layer. 
$\left\{x_{i}\right\}$ : The Input value of the sample, $i=1,2, . ., M$.

$\left\{y_{p}\right\}$ : The output value of the sample $\mathrm{p}$.

$w_{k}$ : The weight of linking hidden layer with output layer, $k=1,2, . ., K$

The output value of the sample $p$ in network:

$$
\begin{gathered}
y_{p}=\sigma\left[\sum_{k=1}^{K} w_{k} \sum_{i=1}^{M} x_{i} \varphi\left(\frac{i-b_{k}}{a_{k}}\right)\right]: \sigma(t)=1 /(1+\exp (-t)) \\
y= \begin{cases}1 & \sigma(t)>0.5 \\
0 & \sigma(t)<0.5\end{cases}
\end{gathered}
$$

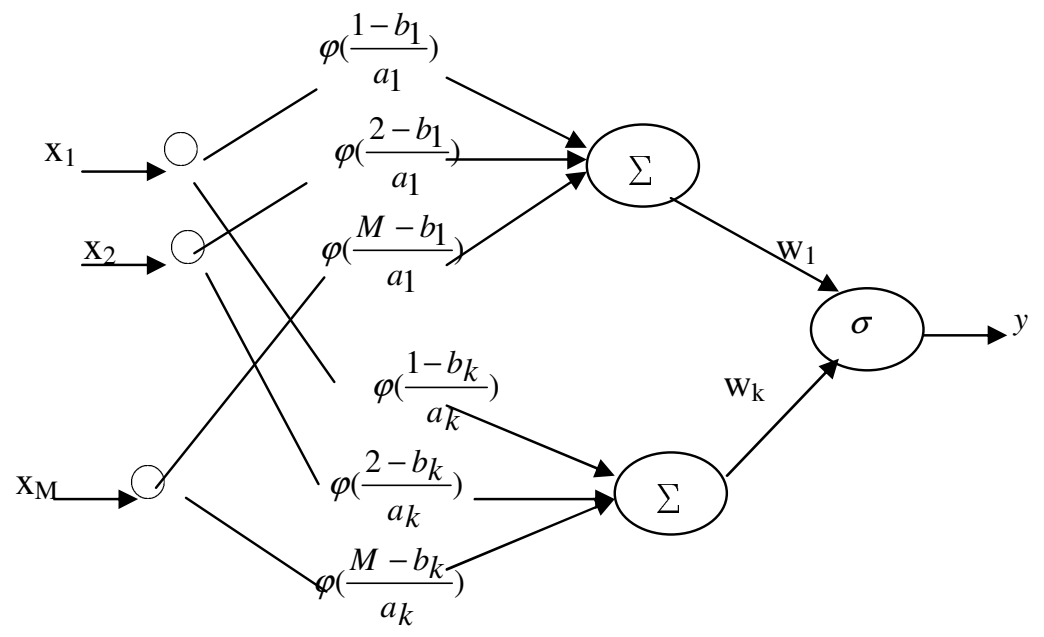

Figure 1: Wavelet neural network structure

The minimum mean error function:

$$
E=\frac{1}{2} \sum_{p=1}^{P}\left\{d p^{-y_{p}}\right)^{2}
$$

Where

$d_{p}:$ The output of expected classification of the sample $\mathrm{p}, d_{p}:=1$ or 0

M: The number of input layer.

$\mathrm{K}$ : The number of hidden layer

$\mathrm{P}$ : The number of sample

\subsection{Wavelet network model training algorithm}

The training algorithm for a wavelet neural network is as follows [35].

(1) Select the no of hidden nodes required. Initialize parameters $a_{k}, b_{k}$, and $w_{k}$ with random number in $[-1,1]$. Give objective mean error $E_{\max }$. The Mother wavelet is has the following form

$$
\begin{aligned}
& \varphi(t)=\cos (1.75 t) \exp \left(-t^{2} / 2\right) \\
& \quad \frac{d \varphi}{d t}=-[t \cos (1.75 t)+1.75 \sin (1.75 t)] \exp \left(-t^{2} / 2\right]
\end{aligned}
$$


When taken as Gaussian wavelet it become

$$
\varphi(t)=\exp \left(-t^{2} / 2\right)
$$

(2) Input training sample $\left\{x_{i}\right\}$ and the objective output $\left\{d_{p}\right\}$. Calculate the output $\left\{y_{p}\right\}$ and he minimum mean error function $\mathrm{E}$.

(3) Adjust $a_{k}, b_{k}$, and $w_{k}$ for reducing the error of production. Use the conjugate gradient descend algorithm is employed:

$$
\begin{array}{r}
w_{k}(t+1)=w_{k}(t)+\eta \frac{\partial E}{\partial w_{k}}+\alpha \Delta w_{k}(t) \\
a_{k}(t+1)=a_{k}(t)+\eta \frac{\partial E}{\partial a_{k}}+\alpha \Delta a_{k}(t) \\
b_{k}(t+1)=b_{k}(t)+\eta \frac{\partial E}{\partial b_{k}}+\alpha \Delta b_{k}(t) \\
t^{\prime}=\frac{i-b_{k}}{a_{k}}
\end{array}
$$

Where

$$
\begin{gathered}
\frac{\partial E}{\partial w_{k}}=-\sum_{p=1}^{P} \sum_{i=1}^{M}\left(d_{p}-y_{p}\right) \sigma^{\prime}\left(t^{\prime}\right) x_{i} \varphi\left(t^{\prime}\right) \\
\frac{\partial E}{\partial a_{k}}=-\sum_{p=1}^{P} \sum_{i=1}^{M}\left(d_{p^{-}} y_{p}\right) w_{k} x_{i} \frac{\partial}{\partial a_{k}} \varphi\left(t^{\prime}\right) \frac{\partial}{\partial a_{k}} \sigma\left(t^{\prime}\right) \\
\frac{\partial E}{\partial b_{k}}=-\sum_{p=1}^{P} \sum_{k=1}^{M}\left(d_{k}^{p}-y_{k}^{p}\right) w_{k} \frac{\partial}{\partial b_{k}} \varphi\left(t^{\prime}\right) \frac{\partial}{\partial b_{k}} \sigma\left(t^{\prime}\right)
\end{gathered}
$$

Where $\eta$ and $\alpha$ are the learning and the momentum rates respectively.

(4) Return to step (2) the process is continued until E satisfies the give error criteria, and the whole training of wavelet neural network is completed.

\subsection{Accuracy rate and error rate}

Since Type I error only creates a lost opportunity cost from not dealing with a successful business, for example, missed potential investment gains [17], therefore Type I error is more important than Type II error. The objectives of predictive of accuracy should be to reduced Type I error while keep Type II error. Table 1 denotes as robustness of model. The measure used for calculating the accuracy of classifying distressed companies and no-distressed companies have:

$$
\begin{aligned}
& \text { Type I error }=\frac{B}{A+B} \\
& \text { Type II error }=\frac{C}{C+D} \\
& \mathrm{E}=A /(A+B) \\
& \mathrm{F}=D /(C+D) \\
& \mathrm{G}=(A+D) /(A+B+C+D)
\end{aligned}
$$


Where

Type I error: refer to the situation when actual failure company is classified as non failures company

Type II error: refer to the situation when actual non failure company is classified as Failures Company.

C: the number of Type I error that is the number of distressed companies in the sample based on actual observation that was misclassified as a non-distressed company.

B: the number of Type II error that is the number of non-distressed companies in the sample based on actual observation that was misclassified as a distressed company.

A: the number of non-distressed accurately classified by the models

D: the number of distressed accurately classified by the models

E: The accuracy of classification of non-distressed company

F: The accuracy of classification of distressed company

G: The oval accuracy of classification

Table 1: Robustness of model

\begin{tabular}{|l|l|l|l|}
\hline $\begin{array}{l}\text { Obse-distressed } \\
\text { Obsed value }\end{array}$ & $\begin{array}{l}\text { Non-distressed } \\
\text { company }\end{array}$ & Distressed company & $\begin{array}{l}\text { Accuracy of } \\
\text { Classification }\end{array}$ \\
\hline Non-distressed company & A & B & E \\
\hline Distressed company & C & D & F \\
\hline $\begin{array}{l}\text { Overall accuracy of } \\
\text { classification }\end{array}$ & & & G \\
\hline
\end{tabular}

\section{EMPRICAL RESEARCH}

We random select in the stock market listed company's traditional manufacturing in Taiwan to analysis the wavelet network model prediction. The steps of business failure prediction model (Wavelet network model and logistic regression model) are:

Step 1: Financial ratio of dataset

Step 2: Identification of independent variables

Step 3: Reduced the number of financial ratio

(a) Kolmogorov-Smirnov test (K-S test)

(b) Wilcoxon test

(c) Principal component analysis

Step 4: Building the wavelet networks model

(a) Wavelet networks model

(b) Training for a wavelet neural network

(c) Robustness of model in prediction accuracy

Step5: Building Logistic regression model

(a) Logistic regression model

(b) Training for Logistic regression

(c) Robustness of model in prediction accuracy

Step 6: Comparison of Wavelet Network and Logistic Regression

\subsection{Financial Ratio of Dataset}

A dataset of covariates used in this study includes a combination of financial ratios and market variables [15]. Some researches such as [3, 8, 9, 23 24, 26 27, 39] have been widely used financial ratios in explaining the possibility of business financial distress. Gibson [14] suggests five factors (Profitability, Liquidity, Leverage, Efficiency, and Valuation ratio) for evaluation enterprise financial failure. Table 3 is the 15 rations selected in this study. 
International Journal of Computer Science \& Information Technology (IJCSIT) Vol 7, No 3, June 2015

Table 3: The 15 rations selected in this study

\begin{tabular}{|c|c|c|c|c|}
\hline & Category & Covariate & Code & Definition \\
\hline $\mathrm{X}_{1}$ & \multirow[t]{3}{*}{ Profitability } & EBIT margin & EBT & EBIT/operating revenue \\
\hline $\mathrm{x}_{2}$ & & Return on Equity & ROE & Net income/ Total equity \\
\hline $\mathrm{X}_{3}$ & & Return on Assets & ROA & Net income/ Total assets \\
\hline $\mathrm{X}_{4}$ & \multirow[t]{2}{*}{ Liquidity } & Current ratio & CUR & Current assets/ current liabilities \\
\hline $\mathrm{X}_{5}$ & & Quick ration & QUK & Quick assets/ current liabilities \\
\hline $\mathrm{x}_{6}$ & \multirow[t]{2}{*}{ Leverage } & Debt ratio & DET & Total liabilities/ Total assets \\
\hline $\mathrm{x}_{7}$ & & Debt to Equity ratio & DER & Total liabilities/ Total equity \\
\hline $\mathrm{x}_{8}$ & \multirow[t]{2}{*}{ Efficiency } & Fixed Asset turnover & FAT & Revenue/Asset \\
\hline $\mathrm{x}_{9}$ & & Capital turnover & CAT & $\begin{array}{l}\text { Operating revenue/ operating invest } \\
\text { capital }\end{array}$ \\
\hline $\mathrm{X}_{10}$ & \multirow{3}{*}{ Valuation ratio } & Price to Sales ratio & PSR & Stock price per share/ Sales per share \\
\hline $\mathrm{x}_{11}$ & & Price earnings ratio & PER & $\begin{array}{l}\text { Stock price per share/Earnings per } \\
\text { share }\end{array}$ \\
\hline $\mathrm{x}_{12}$ & & Price to book value & PBV & $\begin{array}{l}\text { Stock price per share/Equity per } \\
\text { share }\end{array}$ \\
\hline $\mathrm{x}_{13}$ & \multirow[t]{3}{*}{ Growth ability } & Operating Profit grew & OPG & Operating Profit grew rate \\
\hline $\mathrm{X}_{14}$ & & Net profit grow rate & NPG & Net profit grow rate \\
\hline $\mathrm{X}_{15}$ & & Inventory turning rate & ITR & Sale/ Inventory \\
\hline
\end{tabular}

\subsection{Data collection and Sample}

This paper random select sample listed companies from 2006 to 2009 for estimating sample.

\subsection{Reduced the number of financial ratio}

There are three ways to reduce the large number of financial indicators (1) Financial indicators normal distribution test (Kolmogorov-Smirnov test (K-S test)) (2) Paired samples' significant test in financial indicators (Wilcoxon test) (3) Principal component analysis (PCA). PCA is a statistical procedure that uses an orthogonal transformation to convert a set of observations of possibly correlated variables into a set of values of linearly uncorrelated variables called principal components. The number of principal components is less than or equal to the number of original variables.

(1) Kolmogorov-Smirnov test (K-S test)

The K-S test has the advantage of making no assumption about the distribution of data. Suppose that an Independent and Identically Distributed (i.i.d.) sample $x_{1}, x_{2}, \ldots x_{n}$ with some unknown distribution $p$ and we would like to test the hypothesis that $p$ is equal to a particular (normal) distribution $p_{0}$, i.e. decide between the following hypotheses:

$H_{0}: p=p_{0}, H_{1}: p \neq p_{0}$. We know that testing this hypothesis use chi-squared goodness-offit test.

(2) Wilcoxon test (Wilcoxon signed-rank test)

The Wilcoxon signed-rank test is a non-parametric statistical hypothesis test used when comparing two related samples, matched samples, or repeated measurements on a single sample to assess whether their population mean ranks differ (i.e. it is a paired difference test). Wilcoxon test used as (1) an alternative to the paired Student's t-test, (2) $t$-test for matched pairs, (3) the $t$ test for dependent samples when the population cannot be assumed to be normally distributed.

(3) Principal component analysis (PCA) 
The main purposes of a PCA are (1) the analysis of data to identify patterns (2) finding patterns to reduce the dimensions of the dataset with minimal loss of information. In the table of principal component variance, it select no of components in this data testing, according to the cumulative variance above to $95 \%$.

\subsection{Building the wavelet networks model}

In wavelet network model, the numbers of neurons of the input and output layers are respectively equal to the number of variables presented simultaneously to the network and to the number of variables that the neural network must estimate. Wavelet network model the number of principal components is equal to the number of input layer neuron. The number of output layer neuron is 1. The output neuron takes the value 0 if the company is healthy (no-financial distress) and 1 if it is bankrupt (financial distress). To determine the number of hidden layer node is by researcher.

After determining the network architecture, its implementation requires two data samples. The first set of data is used for the training, the second for the validation. The neural network is been realized using Matlab software. Model input values of paired samples are the score value of principal components.

\subsection{Building Logistic regression model}

Logistic regression model input values of paired samples are the score value of principal components. The dependent variable in logistic regression is usually dichotomous, that is, the dependent variable can take the value 1 with a probability of success $p\left(y_{i}\right)$, or the value 0 with probability of failure $1-p\left(y_{i}\right)$.

The Logistic regression is been realized using Spss21.0 software and the Wald statistic for test the $\hat{\beta}$ coefficient.

The predict probability of occurrence $p\left(y_{i}\right)$ given as:

$$
p\left(y_{i}\right)=1 /\left\{1+\exp \left[-\left(\hat{\beta}_{0}+\hat{\beta}_{1} x_{1}+\ldots .+\hat{\beta}_{m} x_{m}\right)\right]\right\}
$$

The output $p\left(y_{i}\right)>0.5$ takes the value 0 , the company is healthy (no-financial distress) and $p\left(y_{i}\right)<0.5$ takes the value 1 , and the company is bankrupt.

\subsection{Robustness of model in prediction accuracy}

It easily calculates the accuracy rate and Error rate. Type I error is $\frac{B}{A+B} \%$ and Type II error is $\frac{C}{C+D} \%($ See Table 1$)$.

\section{EMPIRICAL ANALYSIS}

\subsection{Data collection and Sample}

This paper select sample listed companies from 2006 to 2009 for training sample. There select 40 paired samples for analysis. It randomly selected 20 paired sample listed companies from 2009 to 2012 for forecasting sample. 
Through the kolmogorov- Siminor test (using SPSS20.0 software), no financial indicator on paired sample is normal distribution. Through wilcoxon test, ten variables are selected as potential predictor variables: EBIT margin $\left(\mathrm{x}_{1}\right)$, Return on Equity $\left(\mathrm{x}_{2}\right)$, Return on Assets $\left(\mathrm{x}_{3}\right)$, Current ratio $\left(\mathrm{x}_{4}\right)$, Quick ration $\left(\mathrm{x}_{5}\right)$, Fixed Asset turnover $\left(\mathrm{x}_{8}\right)$, Price earnings ratio $\left(\mathrm{x}_{11}\right)$, Price to book value $\left(\mathrm{x}_{12}\right)$, Operating Profit grew $\left(\mathrm{x}_{13}\right)$, Net profit grow rate $\left(\mathrm{x}_{14}\right)$. The paired financial indicators sample wilcoxon test denotes as Table 4.

Table 4: The paired financial indicators sample wilcoxon test

\begin{tabular}{|l|l|l|l|}
\hline $\begin{array}{l}\text { Financial } \\
\text { indicator }\end{array}$ & $\begin{array}{l}\text { Statistic Z } \\
\text { value }\end{array}$ & 2-taied test p-value & Result \\
\hline $\mathrm{X}_{1}$ (EBIT) & -2.012 & 0.042 & $*$ \\
\hline $\mathrm{X}_{2}$ (ROE) & -3.325 & 0.001 & $*$ \\
\hline $\mathrm{X}_{3}$ (ROA) & -4.855 & 0.000 & $*$ \\
\hline $\mathrm{X}_{4}$ (CUR) & -4.121 & 0.000 & $*$ \\
\hline $\mathrm{X}_{5}$ (QUR) & -1.968 & 0.045 & $*$ \\
\hline $\mathrm{X}_{6}$ (DET) & -1.763 & 0.084 & \\
\hline $\mathrm{X}_{7}$ (DER) & -0.213 & 0.812 & \\
\hline $\mathrm{X}_{8}$ (FAT) & -2.164 & 0.032 & $*$ \\
\hline $\mathrm{X}_{9}$ (CAT) & -1.357 & 0.160 & \\
\hline $\mathrm{X}_{10}$ (PSR) & -1.656 & 0.085 & $*$ \\
\hline $\mathrm{X}_{11}$ (PER) & -3.902 & 0.002 & $*$ \\
\hline $\mathrm{X}_{12}$ (PBV) & -1.993 & 0.047 & $*$ \\
\hline $\mathrm{X}_{13}$ (OPG) & -2.133 & 0.034 & $*$ \\
\hline $\mathrm{X}_{14}$ (NPG) & -3.258 & 0.001 & \\
\hline $\mathrm{X}_{15}$ (ITR) & -1.885 & 0.068 & \\
\hline
\end{tabular}

* Significant at 5 percent level

\subsection{Principal component analyse}

PCA is statistical procedure that uses an orthogonal transformation to convert a set of observations of possibly correlated variables into a set of values of linearly uncorrelated variables. It uses SPSS 21.0 software on PCA. It gets 8 principal components $\left(\mathrm{z}_{1}, \mathrm{z}_{2}, \mathrm{z}_{3}, \mathrm{z}_{4}, \mathrm{z}_{5}, \mathrm{z}_{6}, \mathrm{z}_{7}, \mathrm{z}_{8}\right)$, it contains the original 10 financial indicators $97.82 \%$ (see table 5).

Tab 5: The principal component Variance

\begin{tabular}{|l|l|l|l|}
\hline $\begin{array}{l}\text { Principal } \\
\text { components }\end{array}$ & Eigenvalue & Variance $(\%)$ & $\begin{array}{l}\text { Cumulated Variance } \\
(\%)\end{array}$ \\
\hline $\mathrm{Z}_{1}$ & 3.165 & 31.642 & 31.642 \\
\hline $\mathrm{Z}_{2}$ & 1.315 & 13.043 & 44.685 \\
\hline $\mathrm{Z}_{3}$ & 1.088 & 10.863 & 55.548 \\
\hline $\mathrm{Z}_{4}$ & 0.935 & 9.347 & 64.895 \\
\hline $\mathrm{Z}_{5}$ & 0.921 & 9.225 & 74.120 \\
\hline $\mathrm{Z}_{6}$ & 0.834 & 8.336 & 82.456 \\
\hline $\mathrm{Z}_{7}$ & 0.781 & 7.712 & 90.168 \\
\hline $\mathrm{Z}_{8}$ & 0.753 & 7.652 & 97.820 \\
\hline $\mathrm{Z}_{9}$ & 0.155 & 1.540 & 99.760 \\
\hline $\mathrm{Z}_{10}$ & 0.065 & 0.640 & 100.00 \\
\hline
\end{tabular}

The component score express as:

$$
z_{i}=a_{1 i} x_{1}^{*}+a_{2 i} x_{2}^{*}+a_{3 i} x_{3}^{*}+a_{4 i} x_{4}^{*}+a_{5 i} x_{5}^{*}+a_{8 i} x_{8}^{*}+a_{11 i} x_{11}^{*}+a_{12 i} x_{12}^{*}+a_{13 i} x_{13}^{*}+a_{14 i} x_{14}^{*}
$$


International Journal of Computer Science \& Information Technology (IJCSIT) Vol 7, No 3, June 2015

Where $i=1,2, \ldots ., 8, \quad x_{1}^{*}=x_{i}-\overline{x_{i}} / s_{i}, \overline{x_{i}}$ : the mean of financial indicator, $s_{i}$ : the standard deviation of financial indicator. Table 6 is denoted as the component scored matrix.

For example,

$$
z_{1}=-0.068 x_{1}^{*}-0.03 x_{2}^{*}+0.538 x_{3}^{*}+0.615 x_{4}^{*}-0.056 x_{5}^{*}-0.042 x_{8}^{*}-0.034 x_{11}^{*}-0.052 x_{12}^{*}-0.085 x_{13}^{*}-0.176 x_{14}^{*}
$$

Table 6: The component scored matrix.

\begin{tabular}{|c|c|c|c|c|c|c|c|c|}
\hline $\begin{array}{l}\text { Principal } \\
\text { component }\end{array}$ & $z_{1}$ & $z_{2}$ & $z 3$ & $z 4$ & $z 5$ & $z_{6}$ & $z 7$ & $z 8$ \\
\hline$x_{1}^{*}(\mathrm{EBIT})$ & -0.068 & 0.008 & 0.054 & -0.013 & 0.046 & 0.017 & 0.072 & 0.027 \\
\hline$x_{2}^{*}(\mathrm{ROE})$ & -0.03 & -0.011 & -0.112 & -0.042 & -0.006 & 0.003 & $\begin{array}{l}- \\
0.003-\end{array}$ & -0.041 \\
\hline$x_{3}^{*}(\mathrm{ROA})$ & 0.538 & -0.036 & -0.035 & -0.058 & -0.024 & -0.036 & -0.012 & -0.124 \\
\hline$x_{4}^{*}$ (CUR) & 0.615 & -0.010 & -0.042 & -0.042 & -0.038 & -0.035 & -0.003 & -0.127 \\
\hline$x_{5}^{*}(\mathrm{QUR})$ & -0.056 & 0.040 & 0.019 & 0.016 & 0.011 & 0.986 & 0.006 & -0.011 \\
\hline$x_{8}^{*}(\mathrm{FAT})$ & -0.042 & 0.032 & 0.012 & -0.043 & 0.0031 & 0.036 & 0.052 & 0.053 \\
\hline$x_{11}^{*}(\mathrm{PER})$ & -0.034 & 0.056 & 0.079 & 0.009 & -0.006 & 0.002 & 0.912 & -0.019 \\
\hline$x_{12}^{*}(\mathrm{PBV})$ & -0.052 & 0.031 & 0.048 & -0.007 & 0.589 & 0.017 & -0.054 & -0.078 \\
\hline$x_{13}^{*}(\mathrm{OPG})$ & -0.085 & -0.042 & -0.012 & 0.831 & -0.006 & 0.015 & 0.008 & -00.94 \\
\hline$x_{14}^{*}(\mathrm{NPG})$ & -0.176 & 0.055 & 0.024 & -0.017 & -0.068 & -0.011 & -0.017 & 5.015 \\
\hline
\end{tabular}

\subsection{Wavelet network model training and forecasting}

The wavelet network training and forecasting use Mat lab software. Vector $\left(z_{1}, z_{1}, z_{3}, z_{4}, z_{5}, z_{6}, z_{7}, z_{8}\right)$ is input of this model. Model input values of paired samples are 40, the input layer neuron is 8 . The hidden layer neuron is 6 and the output layer neuron is 1 . Set minimum mean error function $E=0.001, \eta=0.1, \alpha=0.01$. The paired samples are 40 for training test. Predicted results denoted as table 7.

Table 7: Robustness of model (training sample)

\begin{tabular}{|l|l|l|l|}
\hline $\begin{array}{c}\text { No-distressed } \\
\text { Observed value }\end{array}$ & $\begin{array}{l}\text { Non-distressed } \\
\text { company }\end{array}$ & Distressed company & $\begin{array}{l}\text { Accuracy of } \\
\text { Classification (\%) }\end{array}$ \\
\hline Non-distressed company & 38 & 2 & 95 \\
\hline Distressed company & 1 & 39 & 97.5 \\
\hline $\begin{array}{l}\text { Overall accuracy of } \\
\text { classification }\end{array}$ & & & 96.25 \\
\hline
\end{tabular}

Type I error is $\frac{B}{A+B} \%=5 \%$ and Type II error is $=\frac{C}{C+D} \%=2.5 \%$ 
In order to test the predictive capability of model, paired samples are 20 for forecasting test. Predicted results denoted as table 8 .

Table 8: Robustness of model (forecasting sample)

\begin{tabular}{|l|l|l|l|}
\hline $\begin{array}{l}\text { Nodistressed } \\
\text { Observed value }\end{array}$ & $\begin{array}{l}\text { Non-distressed } \\
\text { company }\end{array}$ & Distressed company & $\begin{array}{l}\text { Accuracy of } \\
\text { Classification (\%) }\end{array}$ \\
\hline Non-distressed company & 16 & 4 & 80 \\
\hline Distressed company & 3 & 17 & 85 \\
\hline $\begin{array}{l}\text { Overall accuracy of } \\
\text { classification }\end{array}$ & & & 82.25 \\
\hline
\end{tabular}

Type I error is $\frac{B}{A+B} \%=20 \%$ and Type II error is $=\frac{C}{C+D} \%=15 \%$

\subsection{Logistics regression model training and forecasting}

Model input values of paired samples are 40. Vector $\left(z_{1}, z_{1}, z_{3}, z_{4}, z_{5}, z_{6}, z_{7}, z_{8}\right)$ is input of this model. The Logistic regression is been realized using Spss21.0 software and the Wald statistic for test the $\hat{\beta}$ coefficient. Since

$$
\chi^{2}=\text { Wald }=\left[\beta / \sigma_{\beta}\right]^{2}=24.123
$$

It has $0.1 \%$ significant effective. The logistic regression model is:

$$
p\left(y_{i}\right)=1 /\left\{1+\exp \left[-0.0448-1.286 z_{1}-0.654 z_{2}-0.295 z_{3}-0.879 z_{4}+0.308 z_{5}-2.55 z_{6}+0.985 z_{7}-0.675 z_{8}\right]\right\}
$$

Table 9 is denoted as the results of logistic regression.

Table 9: The results of Logistic regression model

\begin{tabular}{|l|l|l|l|l|l|}
\hline Variable & coefficient & $\begin{array}{l}\text { Standard } \\
\text { deviation }\end{array}$ & Wald statistic & $\begin{array}{l}\text { Degree } \\
\text { freedom }\end{array}$ & probability \\
\hline $\mathrm{Z}_{1}$ & -1.286 & 0.413 & 10.356 & 1 & 0.001 \\
\hline $\mathrm{Z}_{2}$ & -0.654 & 0.346 & 3.378 & 1 & 0.056 \\
\hline $\mathrm{Z}_{3}$ & --0.295 & 0.276 & 1.211 & 1 & 0.294 \\
\hline $\mathrm{Z}_{4}$ & -0.879 & 1.421 & 0.389 & 1 & 0.531 \\
\hline $\mathrm{Z}_{5}$ & 0.308 & 0.324 & 0.926 & 1 & 0.334 \\
\hline $\mathrm{Z}_{6}$ & -2.555 & 1.692 & 1.467 & 1 & 0.224 \\
\hline $\mathrm{Z}_{7}$ & 0.985 & 0.268 & 0.152 & 1 & 0.716 \\
\hline $\mathrm{Z}_{8}$ & -0.675 & 0.311 & 4.971 & 1 & 0.025 \\
\hline constant & -0.448 & 0.388 & 1.273 & 1 & 0.251 \\
\hline
\end{tabular}

Table 10 and table 11 are robustness of model in training and forecasting samples respectively.

Table 10: Robustness of model (training sample)

\begin{tabular}{|l|l|l|l|}
\hline $\begin{array}{c}\text { No-distressed } \\
\text { Observed value }\end{array}$ & $\begin{array}{l}\text { Non-distressed } \\
\text { company }\end{array}$ & Distressed company & $\begin{array}{l}\text { Accuracy of } \\
\text { Classification (\%) }\end{array}$ \\
\hline Non-distressed company & 30 & 10 & 75 \\
\hline Distressed company & 8 & 32 & 80 \\
\hline $\begin{array}{l}\text { Overall accuracy of } \\
\text { classification }\end{array}$ & & & 77.5 \\
\hline
\end{tabular}


Type I error is $\frac{B}{A+B} \%=25 \%$ and Type II error is $=\frac{C}{C+D} \%=20 \%$

Table 11: Robustness of model (forecasting sample)

\begin{tabular}{|l|l|l|l|}
\hline $\begin{array}{l}\text { No-distressed } \\
\text { Observed value }\end{array}$ & $\begin{array}{l}\text { Non-distressed } \\
\text { company }\end{array}$ & Distressed company & $\begin{array}{l}\text { Accuracy of } \\
\text { Classification (\%) }\end{array}$ \\
\hline Non-distressed company & 14 & 6 & 70 \\
\hline Distressed company & 3 & 17 & 85 \\
\hline $\begin{array}{l}\text { Overall accuracy of } \\
\text { classification }\end{array}$ & & & 77.5 \\
\hline
\end{tabular}

Type I error is $\frac{B}{A+B} \%=30 \%$ and Type II error is $=\frac{C}{C+D} \%=15 \%$

\subsection{Comparison of Wavelet Network and Logistic Regression}

In comparison of Wavelet Network and Logistic Regression on training and forecasting sample, from the table 7 , table 8 and table 10, table 11, no matter how the overall prediction accuracy, Type I error and Type II error, wavelet networks model is better than logistic regression model.

\section{CONCLUSION}

This paper select sample listed companies from 2006 to 2009 for training sample. There select 40 paired samples for analysis. It randomly selected 20 paired sample listed companies from 2009 to 2012 for forecasting sample.

Wavelet method and Logistic regression are introduced to suppress the financial distress prediction accuracy degradation due to potential accounting noise. In this paper, it use Kolmogorov-Smirnov test (K-S test), Wilcoxon test, Principal component analysis (PCA) to select potential predictor variables that are informative and closely related to companies' financial condition.

In this paper, it has two experiments to compare the prediction accuracy between Wavelet methods with Logistic regression method. From the results of training and forecasting sample test, the wavelet networks model in this paper on enterprise's financial distress early warning is valid. The result of comparison of Wavelet Network and Logistic Regression denoted as table 12.

Table 12: Comparison of Wavelet Network and Logistic Regression

\begin{tabular}{|c|c|c|c|}
\hline Model & & Training & Forecasting \\
\hline \multirow{3}{*}{$\begin{array}{l}\text { Wavelet } \\
\text { Network model }\end{array}$} & Type I error & 0.05 & 0.2 \\
\hline & Type Ilerror & 0.025 & 0.15 \\
\hline & $\begin{array}{l}\text { Overall accuracy of } \\
\text { classification }\end{array}$ & 0.9625 & 0.8225 \\
\hline \multirow{3}{*}{$\begin{array}{l}\text { Logistic } \\
\text { Regression }\end{array}$} & Type I error & 0.25 & 0.30 \\
\hline & Type Ilerror & 0.2 & 0.15 \\
\hline & $\begin{array}{l}\text { Overall accuracy of } \\
\text { classification }\end{array}$ & 0.775 & 0.775 \\
\hline
\end{tabular}


In Table 12, the comparison of Wavelet Network and Logistic Regression on training and forecasting sample, no matter how the overall prediction accuracy, Type I error and Type II error, wavelet networks model is better than logistic regression model.

\section{ACKNOWLEDGEMENTS}

I would like to thank the anonymous reviewers for their constructive comments on this paper.

\section{REFERENCES}

[1] Adiana, NHA. Halim, A., Ahmad, H., and Rohani, M. R. (2008), "Predicting corporate failure of Malaysia's listed companies: Comparing multiple disrtriminant analysis, logistic regression and the Hazard model". International Research Journal of Finance and Economic, Vol. 5, pp. 202-217.

[2] Altman, E.I. (1968), "Financial Ratios, Discriminant Analysis and the Prediction of Corporate Bankruptcy", Journal of Finance, Vol. 23, September, 189-209.

[3] Antonakis, A. C. and Sfakianakis, M. E., (2009), "Assessing naïve Bayesian as a method of screening credit applications", Journal of applied Statistics, Vol. 36, No. 5, pp. 537-545

[4] Banakar, A., Azeem, M. F., (2006), "A New Artificial Neural Network and its Application in Wavelet Neural Network and Wavelet Neural-Fuzzy Case study: Time Series Prediction”, 3rd International IEEE Conference Intelligent Systems.

[5] Banakar, A., Azeem, M. F., (2008), "Artificial Neural Network and its Application in Neural fuzzy models”, Applied Soft Computing, Vol. 8, No. 4, pp. 1463-1485.

[6] Beaver, W. (1967)." Financial Ratios as Predictors of Failure”, Journal of Accounting Research 4, pp. 71-111.

[7] Becerra, V., Roberta, K. H. G. and Magda, A. S. (2005)," Neural and wavelet models for financial distress classification”, Data mining and Knowledge Discovery, Vol. 11. No. 1, pp. 35-55.

[8] Bongini, P., Ferri, G. and Hahm, H. (2000), "corporate bankruptcy in Korea: Only the strong survival?" Financial Review, Vol. 35, pp. 71-111.

[9] Catanach, A. H. and Perry, S. H. (2001), "An evaluation of survival model's contribution to thrift institution distress prediction", Journal of Managerial Issue, Vol.13,No.4, pp. 401-417

[10] Chaduhuri, A, and De, K., (2011), "Fuzzy support vector machine for bankruptcy prediction", Applied Soft Computing, Vol. 11, No. 2, pp.2472-2486

[11] Chen, D., (2009), "Using neural networks and data mining techniques for financial distress prediction model”. Expert Systems with Application, Vol. 36, No. 2, pp.4075-4086

[12] Donald, B. P. and Andrew, T. W. (2000), "Wavelet methods for time series analysis", Cambridge: Cambridge University press, 2010.

[13] Gepp, A. and Kumar, K. (2008), "The role of survival analysis in financial distress prediction". International Research Journal of Finance and Economic, Vol. 16, pp.13-34.

[14] Gibson, C. H. (2006), "Financial Reporting and analysis: using financial associating information". South-Western College Pub, 10 editions, April, 27.

[15] GIGS (2006): “Global Industry Classification Standard (GICS@)”, Standard \& Poor's, August, 2006

[16] Hong, L. and Guangjun, H. (2004), "Early failure warning of listed companies based on artificial neural network method", Accounting Research, Beijing ,pp. 42 - 46, February 2004.

[17] Lau, S. T., Cheng, B. W., and Hsieh, C. H., (2009), "Prediction model building with clusteringlaunched classification and support vector machines in credit scoring". Expert Systems with Applications, Vol. 36, No. 4, pp. 7526-7556.

[18] Lee, C, and Lin, C., (2003), "A wavelet-based Neuron-fuzzy system and its applications", Proceedings of the International Joint Conference on Neural Networks, IEEE, pp. 1921-1926.

[19] Lin, L. and Piesse, J. (2004), "The identification of corporate distress in UK industrials: A conditional probability analysis approach", Applied Financial Economics, Vol. 14, pp. 73-82

[20] Lineesh, M. C. and C Jessy John, C. J. (2010), "Analysis of No stationary Time Series using Wavelet Decomposition”, Nature and Science, Vol. 1., pp. 53-59.

[21] Lu, S., Ju, K. H. and Chon, K. H. (2001), "A new algorithm for linear and nonlinear ARMA model parameter estimation using affine geometry”, IEEE Transaction Biomedical Engineering, Vol. 48, No, 10, pp. 1116-1124. 
[22] Mcleay, S. and Omar, A. (2000), "The sensitivity of prediction models to the non-normality of bound and unbounded financial ratios", The British Accounting Review, Vol. 32, No. 2, pp. 213-230.

[23] Mossman, C. E., Bell, G. G. Swartz, L. M. and Turtle, H. (1998), "An empirical comparison of bankruptcy models", Financial Review, Vol. 33, No. 2, pp. 35-53.

[24] Ohlson, J. A. (1980), "Financial Ratios and the Probabilistic Prediction of Bankruptcy, Journal of Accounting Research, (spring, 1980), Vol. 14, No. 1, pp. 109-131.

[25] Qin, J. and Zhang, B. (1997), "A goodness of fit test for logistic regression models based on casecontrol data". Biometrika, Vol. 84, pp. 609-618.

[26] Rommer, A. D. (2005), "A comparative analysis of the determinants of financial distress in French", Italian and Spanish firms, Working paper, Dan marks National Bank, Copenhagen. 18, May, 2005.

[27] Routledge, J. and Gadenne, D. (2000), "Financial distress, reorganization and corporate performance", Accounting and Financial, Vol. 40, No. 3, pp. 233-259.

[28] SAS, "The Box-Jenkins methodology for time series model", SAS global Forum 2013, support.sas.com/resources/papers/proceedings 13/454-2013.pdf

[29] Suhartono and Subanar, (2009), "Development of Model Building Procedures in Wavelet Neural Networks for Forecasting Non-Stationary Time Series", European Journal of Scientific Research, Vol. 34, No. 3, pp. 416-427.

[30] Tan, C. N. W. and Dihardjo, H. (2001), "A study on using artificial neural networks to develop an early warning predictor for credit union financial distress with comparison to the probit mode", Managerial Financial, Vol. 27, No. 4, pp. 56-77.

[31] Wang, J., Peng, H., Chen, Y. and Song, Z., (2006), “Adaptive Fuzzy Wavelet Control for a Class of Uncertain Nonlinear Systems". Proceedings of the Fifth International Conference on Machine Learning and Cybernetics, Dalian.

[32] Wu, S., Lu X. (2001),"The Financial Distress Prediction Model of Listed Companies in China", Economic Research, Beijing, pp32-38

[33] Yang, Z., You, W. and Ji, G. (2011), "Using partial least squares and support vector machines for bankruptcy prediction”, Expert Systems with Applications”. Vol.38, No.7, pp. 8336-8342.

[34] Yilmaz, S., and Oysal, Y., (2010), "Fuzzy wavelet neural network models for prediction and identification of dynamical systems", IEEE transactions on neural networks, pp. 1599-1609.

[35] Zhang, B. L., Coggins, K., Jabri, M. A., Dersch, D. and Flower, B. (2001), "Multi-resolution Forecasting for Futures Trading Using Wavelet Decompositions", IEEE Transactions on neural networks, Vol. 12, No. 4,pp. 765-775.

[36] Zhang, J., Walter, G. G., Miao, Y., and Lee, W. N. W. (1995), "Wavelet neural network for function learning”, IEEE Transactions on Signal Processing, Vol. 43, 1485-1497.

[37] Zhang, L. (2000), "Discriminant Analysis Model and Applications on Financial Distress", Forecasting, No. 6. pp 11-13, 2000

[38] Zhang, L., S. Chen, J. Yen, and E. Altman (2007), "Corporate Financial distress Diagnosis in China”. In Working Paper Series: New York University.

[39] Zulkarmain, M. S., Mohamad, A. A. H., Annuar, M. N. and Zainal, A. M. (2001), "Forecasting corporate failure in Malaysian industrial sector firms", Asia Academy of Management Journal, Vol. 6, No.1, pp. 15-30. 